\title{
Expression of podocalyxin-like protein is an independent prognostic biomarker in resected esophageal and gastric adenocarcinoma
}

David Borg ${ }^{*}$ (D), Charlotta Hedner, Björn Nodin, Anna Larsson, Anders Johnsson, Jakob Eberhard and Karin Jirström

\begin{abstract}
Background: Podocalyxin-like protein (PODXL) is a cell surface transmembrane glycoprotein, the expression of which has been associated with poor prognosis in a range of malignancies. The aim of this study was to investigate the impact of PODXL expression on survival in esophageal and gastric adenocarcinoma.

Methods: The study cohort consists of a consecutive series of 174 patients with esophageal (including the gastroesophageal junction) or gastric adenocarcinoma, surgically treated between 2006 and 2010 and not subjected to neoadjuvant treatment. Immunohistochemical expression of PODXL was assessed in tissue microarrays with cores from primary tumors, lymph node metastases, intestinal metaplasia and adjacent normal epithelium. Survival analyses were performed on patients with no distant metastases and no macroscopic residual tumor.

Results: In the majority of cases, expression of PODXL was significantly higher in cancer cells compared to normal epithelial cells and was significantly associated with lymph node metastases and high grade tumors. In esophageal adenocarcinoma, Kaplan-Meier analyses revealed that patients with PODXL negative tumors had a superior time to recurrence (TTR) and overall survival (OS) compared to patients with PODXL positive tumors. In gastric adenocarcinoma, patients with PODXL negative tumors had a superior TTR and a trend towards an improved OS. In esophageal and gastric adenocarcinoma combined, the prognostic significance of PODXL expression on TTR was confirmed in unadjusted Cox regression analysis ( $\mathrm{HR}=5.36,95 \% \mathrm{Cl} 1.68-17.06, p=0.005)$ and remained significant in the adjusted model ( $\mathrm{HR}=3.39,95 \% \mathrm{Cl} 1.01-11.35, p=0.048)$. Moreover, the impact of PODXL expression on OS was also confirmed in unadjusted analysis ( $\mathrm{HR}=2.52,95 \% \mathrm{Cl} 1.31-4.85, p=0.006)$ and remained significant in the adjusted model $(H R=2.03,95 \% \mathrm{Cl} 1.04-3.98, p=0.039)$.
\end{abstract}

Conclusions: In esophageal and gastric adenocarcinoma, PODXL expression is an independent prognostic biomarker for reduced time to recurrence and poor overall survival. This is the first report on the prognostic role of PODXL in esophageal adenocarcinoma and validates recent findings in gastric cancer.

Keywords: Esophageal neoplasms, Stomach neoplasms, Adenocarcinoma, Prognosis, PODXL

\footnotetext{
* Correspondence: david.borg@med.lu.se

Department of Clinical Sciences Lund, Division of Oncology and Pathology,

Lund University, Skåne University Hospital, SE-221 85 Lund, Sweden
} 


\section{Background}

Esophageal and gastric cancers are among the most common types of cancer worldwide in terms of incidence and mortality [1]. Historically, the majority of esophageal cancers were squamous cell carcinomas, but in the last four decades there has been a drastic increase in the incidence of adenocarcinoma, especially in many Western countries, where it is now the most common subtype [2]. Adenocarcinoma in the esophagogastric (EG) junction is, since the 7th edition of the AJCC/UICC TNM staging system [3], classified as esophageal cancer. Proposed risk factors for esophageal and EG junction adenocarcinoma are gastroesophageal reflux disease, obesity and decreased prevalence of Helicobacter pylori infection [4, 5]. Regarding gastric adenocarcinoma, the incidence has been declining for several decades [6], possibly due to improved sanitary conditions and decreased prevalence of Helicobacter pylori infection [7], but globally it is still the 3rd leading cause of cancer death.

In resectable esophageal and gastric cancer, several phase III trials [8-13] have shown that the addition of neoadjuvant and/or adjuvant chemotherapy or chemoradiotherapy improves survival. However, the prognosis is still poor, especially in Western populations, with 5-year survival rates less than $40 \%$.

Hence, in addition to primary prevention and earlier detection, the key to improved outcome for patients with esophageal and gastric cancer is to find more effective treatments and also to personalize the treatment based on prognostic and response predictive factors.

Podocalyxin-like protein (PODXL) is a cell surface transmembrane glycoprotein, belonging to the CD34 family, that is encoded on chromosome 7q32-q33. It was first discovered in renal podocytes as an anti-adhesive protein [14] and has later been shown to be expressed in vascular endothelium [15] and to be involved in hematopoiesis [16] and neural development [17]. PODXL is expressed in a range of malignancies and overexpression has mostly been linked to poor prognosis, e.g. in glioblastoma multiforme [18], breast cancer [19], bladder cancer [20], periampullary and pancreatic adenocarcinoma [21, 22] and colorectal cancer [23-25]. Laitinen et al. [26] recently showed that in surgically treated gastric cancer, patients with PODXL negative tumors had a significantly better cancer-specific 5-year survival than patients with PODXL positive tumors.

The functional role of PODXL in tumorigenesis is largely unknown, but it has been demonstrated to promote cancer cell invasion and migration and to enhance metastatic potential [27-29]. Other proposed mechanisms are evasion of natural killer cell-mediated cytotoxicity [30] and maintaining and regulating the surface expression of glucose transporters [31]. In osteosarcoma cell lines, PODXL has been shown to promote chemoresistance to cisplatin [32], which is particularly interesting since platinum compounds (cisplatin and oxaliplatin) are important cytotoxic drugs in the treatment of esophageal and gastric adenocarcinoma.

To our best knowledge, there are no reports on the prognostic value of PODXL expression in esophageal adenocarcinoma.

The aim of this study was to explore the expression of PODXL in both esophageal and gastric adenocarcinoma and to assess its impact on time to recurrence (TTR) and overall survival (OS) in a consecutive series of patients from southern Sweden, treated surgically between 2006 and 2010, prior to the wide implementation of neoadjuvant treatment.

\section{Methods}

\section{Study design and participants}

The study cohort consists of a consecutive series of 174 patients with chemo-/radiotherapy-naive esophageal (including EG junction) or gastric adenocarcinoma, subjected to surgical resection at the University Hospitals of Lund and Malmö between January 1, 2006 and December 31, 2010. This cohort has been examined in several previous biomarker studies [33-37]. Data on survival and recurrence were updated until December 31, 2014. Tumor location was based on endoscopy findings. Classification of tumor stage was done according to the 7th edition of the UICC/AJCC TNM classification [3]. Histotype according to Laurén [38] was denoted for all tumors as intestinal, mixed or diffuse growth pattern. This classification is generally applied on gastric cancer but can be used also for esophageal and EG junction adenocarcinoma. Residual tumor status was classified as: R0 = no residual tumor (free resection margins according to pathology report), $\mathrm{R} 1$ = possible microscopic residual tumor (narrow or compromised resection margins according to pathology report), $\mathrm{R} 2$ = macroscopic residual tumor (according to surgery report). The vast majority (98.7\%) of the patients were operated on with a curative intent but three patients with known distant metastases (M1-disease) were resected to palliate symptoms from the primary tumor. In 16 patients, M1-disease was revealed either during surgery or in the resected specimens. No patients received neoadjuvant oncological therapy and only a minority $(7.5 \%)$ of the patients received adjuvant treatment (chemo-/radiotherapy). Clinical data, recurrence status and vital status were obtained retrospectively from medical records. Clinicopathological factors and follow-up data are described in Additional file 1.

\section{Tissue microarrays}

Tissue microarrays (TMAs) were constructed using a semi-automated arraying device (TMArrayer ${ }^{\mathrm{Tm}}$, Pathology 
Devices, Westminster, MD, USA). From all 174 primary tumors, duplicate cores $(1 \mathrm{~mm})$ from separate donor blocks were obtained. In 81 cases lymph node metastases were sampled in duplicate cores (each from a separate metastasis if more than one). In addition 1-3 cores from areas with intestinal metaplasia (Barrett's esophagus or gastric intestinal metaplasia) were sampled in 73 cases. Single core samples from adjacent normal esophageal squamous epithelium (96 cases) and normal gastric columnar epithelium (131 cases) were also retrieved. All samples were paired.

\section{Immunohistochemistry}

For immunohistochemical analysis of PODXL expression, $4 \mu \mathrm{m}$ TMA-sections were automatically pre-treated using the PT Link system and then stained in an Autostainer Plus (DAKO; Glostrup, Copenhagen, Denmark) with the rabbit polyclonal anti-PODXL antibody HPA002110 (Atlas Antibodies AB, Stockholm, Sweden) diluted 1:250. The same antibody was used by Laitinen et al. in their study on gastric cancer [26], and the specificity of the antibody has been validated previously [39]. Staining was assessed simultaneously by two different observers (KJ and $\mathrm{DB}$ ) blinded to clinical and outcome data and scoring discrepancies were discussed to reach consensus. As in previous studies from our group [20, 21, 24, 25, 40], assessment of PODXL staining was registered as negative (0), weak cytoplasmic positivity in any proportion of cells (1), moderate cytoplasmic positivity in any proportion of cells (2), distinct membranous positivity in $\leq 50 \%$ of cells (3) and distinct membranous positivity in $>50 \%$ of cells (4). For samples with duplicate cores the highest staining score was used.

\section{Statistical analysis}

For description of the cohort and in the analyses of the association between PODXL expression and clinicopathological factors, chi-square test (Fisher's exact for $2 \times 2$ tables and linear-by-linear association for tables with more than two rows) was used for categorical variables and Mann-Whitney $U$ test for continuous variables. The Mann-Whitney $U$ test was used to assess differences in PODXL expression between tissue types. In the analyses of the association between PODXL expression and clinicopathological factors and in the survival analyses, a dichotomized variable of negative (staining score 0 ) vs. positive (staining score 1-4) PODXL expression in the primary tumor and/or lymph node metastases was applied. The cut-off between negative and positive PODXL expression was the same as used in the study by Laitinen et al. in gastric cancer [26]. TTR was defined as time from diagnosis (date of result of the preoperative biopsy) to the date of biopsy or radiology proven recurrent disease. OS was defined as time from diagnosis (date of result of the preoperative biopsy) to the date of death. TTR and OS were analyzed for resected patients with M0-disease and no macroscopic residual tumor (R0-1). Differences in Kaplan-Meier survival curves were computed using log-rank test. Unadjusted and adjusted hazard ratios (HR) for survival were determined using Cox proportional-hazards regression. For TTR we adjusted for $\mathrm{T}$ stage, $\mathrm{N}$ stage, $\mathrm{R}$ classification, differentiation grade and adjuvant treatment. For OS, the adjusted model included age, $\mathrm{T}$ stage, $\mathrm{N}$ stage, $\mathrm{R}$ classification and differentiation grade. All tests were 2 -sided and a $p$-value $<0.05$ was considered significant. IBM $^{\circ}$ SPSS $^{\bullet}$ Statistics version 22.0.0.1 for Mac was used for all statistical analyses.

\section{Results}

PODXL expression in normal epithelium, intestinal metaplasia, primary tumors and lymph node metastases Immunohistochemical expression of PODXL could be assessed in 50/96 (52 \%) samples with normal esophageal squamous epithelium, 79/131 (60\%) samples with normal gastric columnar epithelium, 51/73 (70 \%) samples with intestinal metaplasia (Barrett's esophagus or gastric intestinal metaplasia), 170/174 (98 \%) samples with primary tumors, and 76/81 (94\%) samples with lymph node metastases. PODXL staining was mainly detected in the cytoplasm, sometimes in a granular pattern, with or without an accentuation towards the membrane, and in some cases with a strong membranous component. Sample images are shown in Fig. 1. As expected there was a strong staining in endothelial cells, thus serving as an internal positive control. The distribution of immunohistochemical expression of PODXL in the different tissue types is shown in Fig. 2. Expression of PODXL was significantly higher in intestinal metaplasia (Barrett's esophagus or gastric intestinal metaplasia) compared to normal epithelium $(p<0.001)$ and PODXL expression was significantly higher in primary tumors and lymph node metastases compared to intestinal metaplasia $(p<0.001)$. PODXL expression was similar in Barrett's esophagus and gastric intestinal metaplasia $(p=$ 0.671 , data not shown). There was no significant difference in PODXL expression between primary tumors and lymph node metastases $(p=0.645)$ and PODXL expression in primary tumors and/or lymph node metastases did not differ significantly by primary tumor location $(p=0.314$, data not shown).

\section{Associations of PODXL expression with clinicopathological factors}

As shown in Table 1, factors significantly associated with PODXL expression were $\mathrm{N}$ stage and high grade tumors. Negative PODXL expression was denoted in $14.2 \%$ of the esophageal cancers and in $21.5 \%$ of the gastric 

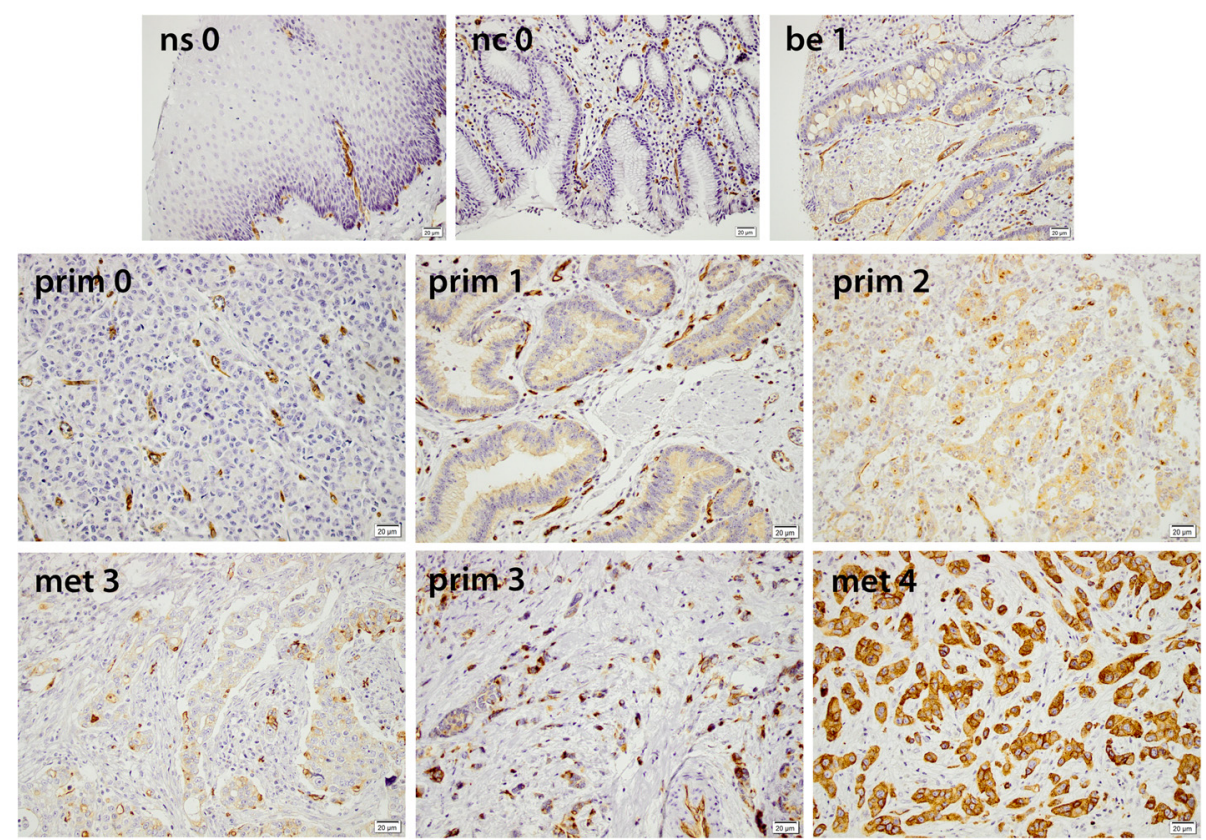

Fig. 1 Sample immunohistochemical images of PODXL expression (staining score 0-4), magnification $\times 20$. Top panel, from left: Normal squamous epithelium (0). Normal columnar epithelium (0). Barrett's esophagus (1). Middle panel, from left: Primary gastric adenocarcinoma, diffuse subtype (0). Primary gastric adenocarcinoma, intestinal subtype (1). Primary gastric adenocarcinoma, intestinal subtype (2). Bottom panel, from left: Lymph node metastasis, intestinal subtype (3). Primary esophageal adenocarcinoma, diffuse subtype (3). Lymph node metastasis, intestinal subtype (4)

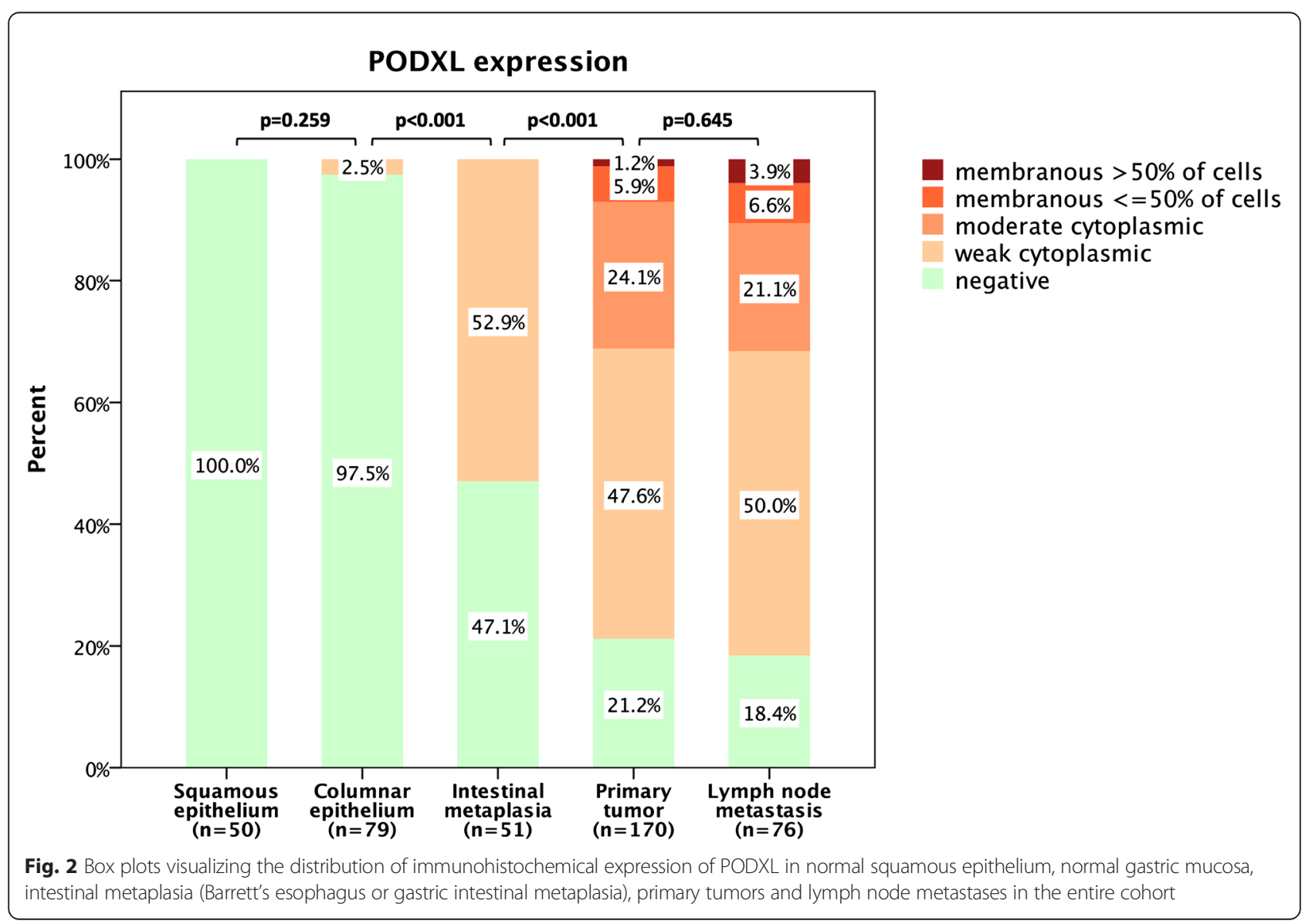


Table 1 Associations of PODXL expression with clinicopathological factors

\begin{tabular}{|c|c|c|c|c|}
\hline & Entire cohort & PODXL neg & PODXL pos & \\
\hline & n (\%) & n (\%) & n (\%) & $p$-value \\
\hline & $171(100.0)$ & $29(17.0)$ & $142(83.0)$ & \\
\hline \multicolumn{5}{|l|}{ Age } \\
\hline$\leq 70$ & $85(49.7)$ & $12(41.4)$ & $73(51.4)$ & 0.416 \\
\hline$>70$ & $86(50.3)$ & $17(58.6)$ & 69 (48.6) & \\
\hline \multicolumn{5}{|l|}{ Sex } \\
\hline Female & $39(22.8)$ & $9(31.0)$ & $30(21.1)$ & 0.330 \\
\hline Male & $132(77.2)$ & $20(69.0)$ & $112(78.9)$ & \\
\hline \multicolumn{5}{|l|}{ T stage } \\
\hline $\mathrm{T} 1$ & $18(10.5)$ & $2(6.9)$ & $16(11.3)$ & 0.637 \\
\hline $\mathrm{T} 2$ & $32(18.7)$ & $6(20.7)$ & $26(18.3)$ & \\
\hline T3 & $94(55.0)$ & $16(55.2)$ & $78(54.9)$ & \\
\hline T4 & $27(15.8)$ & $5(17.2)$ & $22(15.5)$ & \\
\hline \multicolumn{5}{|l|}{ N stage } \\
\hline NO & $57(33.3)$ & $16(55.2)$ & $41(28.9)$ & 0.006 \\
\hline N1 & $29(17.0)$ & $4(13.8)$ & 25 (17.6) & \\
\hline N2 & $41(24.0)$ & $6(20.7)$ & 35 (24.6) & \\
\hline N3 & $44(25.7)$ & $3(10.3)$ & $41(28.9)$ & \\
\hline \multicolumn{5}{|l|}{ M stage } \\
\hline Mo & $152(88.9)$ & $25(86.2)$ & $127(89.4)$ & 0.535 \\
\hline M1 & $19(11.1)$ & $4(13.8)$ & 15 (10.6) & \\
\hline \multicolumn{5}{|l|}{ R classification } \\
\hline RO & $117(68.4)$ & $22(75.9)$ & $95(66.9)$ & 0.556 \\
\hline R1 & $45(26.3)$ & $5(17.2)$ & $40(28.2)$ & \\
\hline R2 & $9(5.3)$ & $2(6.9)$ & $7(4.9)$ & \\
\hline \multicolumn{5}{|l|}{ Differentiation grade } \\
\hline Low grade & $8(4.7)$ & $4(13.8)$ & $4(2.8)$ & 0.023 \\
\hline Intermediate grade & $52(30.4)$ & $10(34.5)$ & $42(29.6)$ & \\
\hline High grade & $111(64.9)$ & $15(51.7)$ & $96(67.6)$ & \\
\hline \multicolumn{5}{|l|}{ Lauren classification } \\
\hline Intestinal & $119(69.6)$ & $23(79.3)$ & $96(67.6)$ & 0.335 \\
\hline Mixed & $9(5.3)$ & $0(0.0)$ & $9(6.3)$ & \\
\hline Diffuse & $43(25.1)$ & $6(20.7)$ & $37(26.1)$ & \\
\hline \multicolumn{5}{|l|}{ Location } \\
\hline $\begin{array}{l}\text { Esophagus + EG } \\
\text { junction }\end{array}$ & $106(62.0)$ & $15(51.7)$ & $91(64.1)$ & 0.217 \\
\hline Stomach & 65 (38.0) & $14(48.3)$ & $51(35.9)$ & \\
\hline
\end{tabular}

$\mathrm{R} 0=$ no residual tumor (free resection margins according to pathology report), $\mathrm{R} 1=$ possible microscopic residual tumor (narrow or compromised resection margins according to pathology report), R2 = macroscopic residual tumor (according to surgery report)

$\mathrm{N} 1=$ metastasis in 1-2 regional lymph nodes, $\mathrm{N} 2=$ metastasis in 3-6 regional lymph nodes, N3 = metastasis in 7 or more regional lymph nodes

The dichotomized variable for age is based on the mean/median age, as shown in Additional file 1 cancers, but the difference between locations was not statistically significant.

\section{Impact of PODXL expression on prognosis}

Survival analyses were performed on patients with $\mathrm{M} 0$ disease and no macroscopic residual tumor (R0-1). In esophageal adenocarcinoma the Kaplan-Meier analyses (Fig. 3a, c) revealed that patients with PODXL negative tumors had a superior TTR (estimated recurrence-free rate at 5 years $75 \%$ vs. $35 \%$ ) and OS (estimated surviving rate at 5 years $69 \%$ vs. $28 \%$ ) compared to patients with PODXL positive tumors. In gastric adenocarcinoma, patients with PODXL negative tumors had a superior TTR (estimated recurrence-free rate at 5 years $88 \%$ vs. $45 \%$ ) and a trend towards an improved OS (estimated surviving rate at 5 years $55 \%$ vs. $40 \%$ ) in the Kaplan-Meier analyses (Fig. 3b, d). In esophageal and gastric adenocarcinoma combined, as shown in Table 2, the prognostic significance of PODXL expression on TTR was confirmed in unadjusted Cox regression analysis $(\mathrm{HR}=5.36,95 \% \mathrm{CI}$ 1.68-17.06, $p=0.005)$ and remained significant in the adjusted model $(\mathrm{HR}=3.39$, $95 \%$ CI 1.01-11.35, $p=0.048)$. Moreover, the impact of PODXL expression on OS was also confirmed in unadjusted analysis ( $\mathrm{HR}=2.52$, $95 \% \mathrm{CI} 1.31-4.85, p=$ $0.006)$ and remained significant in the adjusted model $(\mathrm{HR}=2.03,95 \%$ CI 1.04-3.98, $p=0.039)$.

Similar results were obtained when the survival analyses were stratified by primary tumor location (Additional file 2), and when considering PODXL expression in primary tumors and lymph node metastases separately (Additional file 3).

\section{Discussion}

In this study on resected esophageal and gastric adenocarcinoma we have shown that PODXL is expressed in the majority of cases and correlates with poor survival, but in the subgroup of patients with PODXL negative cancers the prognosis was excellent. This finding applies to both esophageal and gastric cancer with regard to both TTR and OS. To our best knowledge, this is the first report on the prognostic role of PODXL in esophageal adenocarcinoma. Furthermore, in gastric cancer, we have validated the recent findings from Laitinen et al. [26] of a negative prognostic impact of PODXL expression, even though the proportion of PODXL negative gastric cancer cases were lower in our study $(21.5 \%$ compared to $42.5 \%$ ). The reasons for this discrepancy are not clear, since we used the same polyclonal antibody and the same definition for negative vs. positive PODXL expression. However, whereas Laitinen et al. only examined primary tumors, we also included lymph node metastases in our analyses. This resulted in a nonsignificant $(p=0.506)$ decrease in PODXL negative gastric 


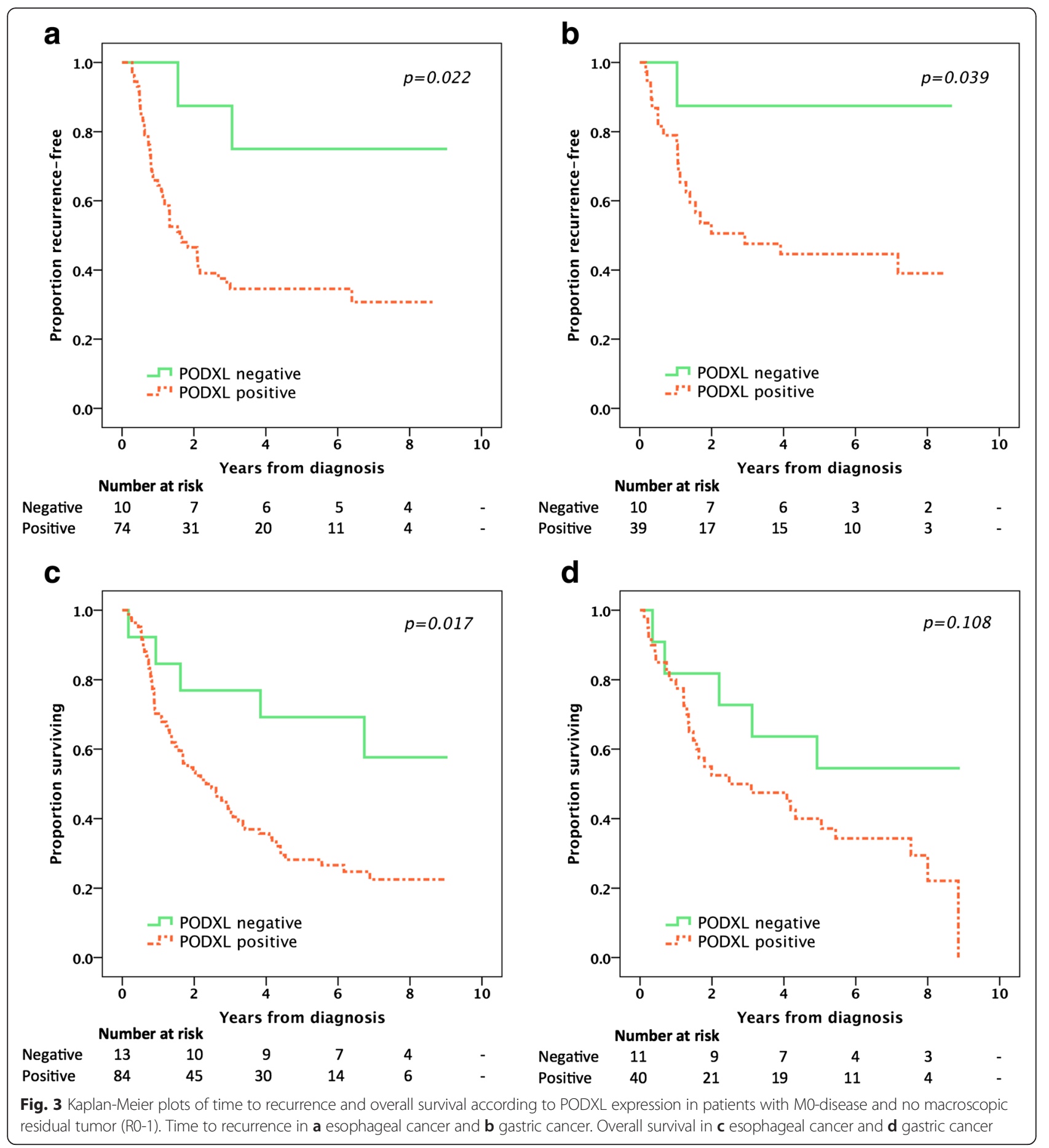

cancer cases from 26.6 to $21.5 \%$. Another factor could be observer-dependent, such as setting the cutoff between negative and weak cytoplasmic staining. In other reports on PODXL as a prognostic marker in colorectal $[23-25,40]$, pancreatic and periampullary adenocarcinoma [21, 22], using the same polyclonal antibody, the most evident prognostic cut-off was observed for membranous vs. non-membranous expression, with the former being an independent factor of poor prognosis. However, in our study and in the report from Laitinen et al., the optimal prognostic cut-off was negative vs. positive, including membranous, PODXL expression. Hence, further studies are warranted to determine optimal cut-offs for prognostication, which may well differ between different types of cancer. Of note, previous studies on colorectal [41] and pancreatic [22] cancer, using a monoclonal anti-PODXL 
Table 2 Hazard ratios for recurrence and death (MO, RO-1)

\begin{tabular}{|c|c|c|c|c|c|c|c|c|c|c|}
\hline & \multicolumn{5}{|c|}{ Time to recurrence } & \multicolumn{5}{|c|}{ Overall survival } \\
\hline & \multirow[b]{2}{*}{$n$ (events) } & \multicolumn{2}{|l|}{ Unadjusted } & \multicolumn{2}{|l|}{ Adjusted } & \multirow[b]{2}{*}{$n$ (events) } & \multicolumn{2}{|l|}{ Unadjusted } & \multicolumn{2}{|l|}{ Adjusted } \\
\hline & & $\mathrm{HR}(95 \% \mathrm{Cl})$ & $\overline{p \text {-value }}$ & HR (95 \% Cl) & $p$-value & & HR $(95 \% \mathrm{Cl})$ & $\overline{p \text {-value }}$ & HR (95 \% Cl) & $\overline{p \text {-value }}$ \\
\hline \multicolumn{11}{|l|}{ Age } \\
\hline Continuous & $136(72)$ & $1.00(0.98-1.02)$ & 0.610 & & & $151(104)$ & $1.04(1.02-1.06)$ & $<0.001$ & $1.05(1.03-1.07)$ & $<0.001$ \\
\hline \multicolumn{11}{|l|}{ Sex } \\
\hline Female & $27(12)$ & & & & & $30(22)$ & & & & \\
\hline Male & $109(60)$ & $1.18(0.63-2.19)$ & 0.610 & & & $121(82)$ & $0.81(0.50-1.29)$ & 0.370 & & \\
\hline T stage & & & $<0.001$ & & 0.043 & & & 0.010 & & 0.511 \\
\hline $\mathrm{T} 1$ & $18(3)$ & & & & & $19(7)$ & & & & \\
\hline $\mathrm{T} 2$ & 27 (8) & $2.14(0.57-8.06)$ & 0.263 & $1.53(0.39-5.96)$ & 0.538 & $30(19)$ & $2.09(0.88-4.97)$ & 0.097 & $1.53(0.62-3.78)$ & 0.357 \\
\hline T3 & $77(51)$ & $6.92(2.15-22.29)$ & 0.001 & $3.72(1.10-12.64)$ & 0.035 & $86(66)$ & $3.27(1.49-7.15)$ & 0.003 & $1.79(0.79-4.08)$ & 0.164 \\
\hline T4 & $14(10)$ & $8.52(2.33-31.16)$ & 0.001 & $3.52(0.92-13.56)$ & 0.067 & $16(12)$ & $3.71(1.45-9.48)$ & 0.006 & $1.98(0.74-5.31)$ & 0.175 \\
\hline \multicolumn{11}{|l|}{ N stage } \\
\hline No & $50(7)$ & & & & & $53(26)$ & & & & \\
\hline $\mathrm{N} 1-3$ & $86(65)$ & $9.89(4.51-21.72)$ & $<0.001$ & $7.78(3.24-18.71)$ & $<0.001$ & $98(78)$ & $2.56(1.63-4.00)$ & $<0.001$ & $2.79(1.67-4.66)$ & $<0.001$ \\
\hline \multicolumn{11}{|l|}{ R classification } \\
\hline Ro & $103(46)$ & & & & & $113(69)$ & & & & \\
\hline R1 & $33(26)$ & $2.89(1.76-4.74)$ & $<0.001$ & $1.38(0.79-2.41)$ & 0.253 & $38(35)$ & $2.75(1.80-4.20)$ & $<0.001$ & $2.07(1.29-3.31)$ & 0.003 \\
\hline \multicolumn{11}{|l|}{ Differentiation grade } \\
\hline Low/Intermediate grade & $49(18)$ & & & & & $56(31)$ & & & & \\
\hline High grade & $87(54)$ & $2.22(1.30-3.79)$ & 0.004 & $1.93(1.09-3.42)$ & 0.025 & $95(73)$ & $1.73(1.13-2.63)$ & 0.011 & $1.40(0.88-2.20)$ & 0.153 \\
\hline \multicolumn{11}{|l|}{ Lauren classification } \\
\hline Intestinal & $94(45)$ & & & & & $106(69)$ & & & & \\
\hline Diffuse/Mixed & $42(27)$ & $1.57(0.97-2.53)$ & 0.064 & & & $45(35)$ & $1.35(0.90-2.03)$ & 0.149 & & \\
\hline \multicolumn{11}{|l|}{ Adjuvant treatment } \\
\hline No & $126(63)$ & & & & & $138(94)$ & & & & \\
\hline Chemo-/radiotherapy & $10(9)$ & $2.12(1.05-4.28)$ & 0.036 & $0.96(0.45-2.06)$ & 0.924 & $13(10)$ & $1.20(0.62-2.30)$ & 0.589 & & \\
\hline \multicolumn{11}{|l|}{ Location } \\
\hline Esophagus + EG junction & $86(49)$ & & & & & $99(69)$ & & & & \\
\hline Stomach & $50(23)$ & $0.74(0.45-1.22)$ & 0.239 & & & $52(35)$ & $0.90(0.60-1.34)$ & 0.592 & & \\
\hline \multicolumn{11}{|l|}{ PODXL expression } \\
\hline Negative & $20(3)$ & & & & & $24(10)$ & & & & \\
\hline Positive & $113(67)$ & $5.36(1.68-17.06)$ & 0.005 & $3.39(1.01-11.35)$ & 0.048 & $124(92)$ & $2.52(1.31-4.85)$ & 0.006 & $2.03(1.04-3.98)$ & 0.039 \\
\hline
\end{tabular}


antibody, demonstrated a correlation between cytoplasmic PODXL expression and poor survival.

A limitation of this study is its retrospective design. However, we have managed to access all the necessary clinical data, except for recurrence status in some cases, and the tissue specimens have been thoroughly re-examined. Due to heterogeneity within tumors there is always a risk of sampling bias with the TMA-technique. However, as we used duplicate cores from different donor blocks and, when available, also included cores from lymph node metastases when denoting the highest PODXL score for each case, the risk of overestimating the proportion of PODXL negative cancers should be reduced.

In current practice, most patients with resectable esophageal or gastric adenocarcinoma receive neoadjuvant and/or adjuvant chemotherapy or chemoradiotherapy, but only a minority (10-15\%) of the patients actually benefit from the oncological treatment [8-13]. For a biomarker to be really useful in clinical decision making it should not only be prognostic but also be able to predict whether a patient will benefit from a treatment or not. Further studies on PODXL in esophageal and gastric adenocarcinoma are warranted to validate its role as a prognostic biomarker and to explore whether it also may be useful as a treatment response predictive biomarker, as suggested in previous studies on colorectal [24] and periampullary cancer [21].

\section{Conclusions}

In summary, we have shown that PODXL is commonly expressed in esophageal and gastric adenocarcinoma and associated with lymph node metastases and high grade tumors. Furthermore, PODXL is an independent prognostic biomarker for reduced time to recurrence and poor overall survival, but in the subgroup of patients with PODXL negative tumors the prognosis appears to be excellent.

\section{Additional files}

\section{Additional file 1: Table S1. Detailed description of the cohort.} (DOCX $19 \mathrm{~kb})$

Additional file 2: Table S2. Hazard ratios for recurrence and death stratified by primary tumor location. (DOCX $18 \mathrm{~kb}$ )

Additional file 3: Table S3. Hazard ratios for recurrence and death stratified by PODXL expression in primary tumors or lymph node metastases (separately and combined). (DOCX $18 \mathrm{~kb}$ )

\section{Abbreviations}

$\mathrm{Cl}$, confidence interval; EG, esophagogastric; $H R$, hazard ratio; IHC, immunohistochemistry; OS, overall survival; PODXL, podocalyxin-like protein; TMA, tissue microarray; TTR, time to recurrence

Acknowledgements

None.

\section{Funding}

This study was supported by grants from the Knut and Alice Wallenberg Foundation, the Swedish Cancer Society, the Crafoord Foundation, the Olle Engkvist Foundation, Anna Lisa and Sven-Eric Lundgren's Foundation, the Swedish Government Grant for Clinical Research (ALF), Lund University Faculty of Medicine and Skåne University Hospital Funds and Donations.

\section{Availability of data and materials}

The raw data set will not be shared since it contains a substantial amount of direct and indirect patient identifying information risking confidentiality. Furthermore, the majority of the patients now being deceased hinders obtaining consent for publication of raw data.

\section{Authors' contributions}

DB evaluated the immunohistochemical stainings, re-examined clinicopathological data, updated survival data, performed the statistical analyses and drafted the manuscript. CH collected and re-examined clinicopathological data and assisted with the TMA construction. BN constructed the TMA and performed the IHC stainings. AL, AJ and JE contributed with intellectual input and contributed to the study design . KJ evaluated the immunohistochemical stainings and conceived of the study. All authors read and approved the final manuscript.

\section{Authors' information}

None.

Competing interests

The authors declare that they have no competing interests.

\section{Consent for publication}

Not applicable.

\section{Ethics approval and consent to participate}

The study was approved by the regional ethics committee at Lund University (ref $\mathrm{nr}$ 445/07), whereby the committee waived the need for consent other than by the option to opt out.

Received: 23 February 2016 Accepted: 20 July 2016

Published online: 29 July 2016

References

1. Ferlay J, Soerjomataram I, Ervik M, Dikshit R, Eser S, Mathers C, Rebelo M, Parkin D, Forman D, Bray F: GLOBOCAN 2012 v1.0, Cancer Incidence and Mortality Worldwide: IARC CancerBase No. 11. Lyon, France: 2013. http:// globocan.iarc.fr, accessed on 6 Feb 2016.

2. Edgren G, Adami H-O, Weiderpass E, Nyrén O. A global assessment of the oesophageal adenocarcinoma epidemic. Gut. 2013;62:1406-14.

3. Sobin L, Gospodarowicz M, Wittekind C. TNM Classification of Malignant Tumours, 7th Edition. Wiley-Blackwell; 2009. http://eu.wiley.com/WileyCDA/ WileyTitle/productCd-1444332414.html.

4. Carr JS, Zafar SF, Saba N, Khuri FR, El-Rayes BF. Risk factors for rising incidence of esophageal and gastric cardia adenocarcinoma. J Gastrointest Cancer. 2013;44:143-51.

5. Nie S, Chen T, Yang X, Huai P, Lu M. Association of Helicobacter pylori infection with esophageal adenocarcinoma and squamous cell carcinoma: a meta-analysis. Dis Esophagus. 2014;27:645-53.

6. Ferro A, Peleteiro B, Malvezzi M, Bosetti C, Bertuccio P, Levi F, Negri E, La Vecchia C, Lunet N. Worldwide trends in gastric cancer mortality (19802011), with predictions to 2015, and incidence by subtype. Eur J Cancer. 2014:50:1330-44.

7. Fuccio L, Eusebi L, Bazzoli F. Gastric cancer, Helicobacter pylori infection and other risk factors. World J Gastrointest Oncol. 2010;2:342.

8. Smalley SR, Benedetti JK, Haller DG, Hundahl SA, Estes NC, Ajani JA, Gunderson LL, Goldman B, Martenson JA, Jessup JM, Stemmermann GN, Blanke CD, Macdonald JS. Updated analysis of SWOG-directed intergroup study 0116: a phase III trial of adjuvant radiochemotherapy versus observation after curative gastric cancer resection. J Clin Oncol. 2012;30:2327-33.

9. Van Hagen $P$, Hulshof $M$, van Lanschot JJB, Steyerberg EW, Henegouwen M van B, Wijnhoven BPL, Richel DJ, Nieuwenhuijzen GAP, Hospers GAP, Bonenkamp JJ. Preoperative chemoradiotherapy for esophageal or junctional cancer. N Engl J Med. 2012;366:2074-84. 
10. Cunningham D, Allum WH, Stenning SP, Thompson JN, Van de Velde CJ, Nicolson M, Scarffe JH, Lofts FJ, Falk SJ, Iveson TJ. Perioperative chemotherapy versus surgery alone for resectable gastroesophageal cancer. N Engl J Med. 2006:355:11-20.

11. Ychou M, Boige V, Pignon J-P, Conroy T, Bouche O, Lebreton G, Ducourtieux M, Bedenne L, Fabre J-M, Saint-Aubert B, Geneve J, Lasser P, Rougier P. Perioperative chemotherapy compared with surgery alone for resectable gastroesophageal adenocarcinoma: an FNCLCC and FFCD multicenter phase III trial. J Clin Oncol. 2011;29:1715-21.

12. Noh SH, Park SR, Yang H-K, Chung HC, Chung I-J, Kim S-W, Kim H-H. Adjuvant capecitabine plus oxaliplatin for gastric cancer after D2 gastrectomy (CLASSIC): 5-year follow-up of an open-label, randomised phase 3 trial. Lancet Oncol. 2014;15:1389-96.

13. Sasako M, Sakuramoto S, Katai H, Kinoshita T, Furukawa H, Yamaguchi T, Nashimoto A, Fujii M, Nakajima T, Ohashi Y. Five-year outcomes of a randomized phase III trial comparing adjuvant chemotherapy with S-1 versus surgery alone in stage II or III gastric cancer. J Clin Oncol. 2011;29:4387-93.

14. Kerjaschki D, Sharkey DJ, Farquhar MG. Identification and characterization of podocalyxin - the major sialoprotein of the renal glomerular epithelial cell. J Cell Biol. 1984;98:1591-6.

15. Horvat R, Hovorka A, Dekan G, Poczewski H, Kerjaschki D. Endothelial cell membranes contain podocalyxin-the major sialoprotein of visceral glomerular epithelial cells. J Cell Biol. 1986;102:484-91.

16. Kerosuo L, Juvonen E, Alitalo R, Gylling M, Kerjaschki D, Miettinen A. Podocalyxin in human haematopoietic cells. Br J Haematol. 2004;124:809-18,

17. Vitureira N, Andrés R, Pérez-Martínez E, Martínez A, Bribián A, Blasi J, Chelliah S, López-Doménech G, De Castro F, Burgaya F, McNagny K, Soriano E. Podocalyxin is a novel polysialylated neural adhesion protein with multiple roles in neural development and synapse formation. PLoS One. 2010;5:e12003.

18. Binder ZA, Siu I-M, Eberhart CG, ap Rhys C, Bai R-Y, Staedtke V, Zhang H, Smoll NR, Piantadosi S, Piccirillo SG, DiMeco F, Weingart JD, Vescovi A, Olivi A, Riggins GJ, Gallia GL. Podocalyxin-like protein is expressed in glioblastoma multiforme stem-like cells and is associated with poor outcome. PLoS One. 2013:8:e75945.

19. Somasiri A, Nielsen JS, Makretsov N, McCoy ML, Prentice L, Gilks CB, Chia SK, Gelmon KA, Kershaw DB, Huntsman DG, et al. Overexpression of the antiadhesin podocalyxin is an independent predictor of breast cancer progression. Cancer Res. 2004;64:5068-73.

20. Boman K, Larsson AH, Segersten U, Kuteeva E, Johannesson H, Nodin B, Eberhard J, Uhlén M, Malmström P-U, Jirström K. Membranous expression of podocalyxin-like protein is an independent factor of poor prognosis in urothelial bladder cancer. Br J Cancer. 2013;108:2321-8.

21. Heby M, Elebro J, Nodin B, Jirström K, Eberhard J. Prognostic and predictive significance of podocalyxin-like protein expression in pancreatic and periampullary adenocarcinoma. BMC Clin Pathol. 2015;15:10.

22. Saukkonen $K$, Hagström J, Mustonen $H$, Juuti A, Nordling S, Fermér C, Nilsson $\mathrm{O}$, Seppänen $\mathrm{H}$, Haglund $\mathrm{C}$. Podocalyxin is a marker of poor prognosis in pancreatic ductal adenocarcinoma. PLoS One. 2015;10:e0129012.

23. Kaprio T, Hagström J, Fermér $C$, Mustonen $H$, Böckelman $C$, Nilsson $\mathrm{O}$, Haglund C. A comparative study of two PODXL antibodies in 840 colorectal cancer patients. BMC Cancer. 2014;14:1.

24. Larsson A, Johansson ME, Wangefjord S, Gaber A, Nodin B, Kucharzewska P, Welinder C, Belting M, Eberhard J, Johnsson A, Uhlén M, Jirström K. Overexpression of podocalyxin-like protein is an independent factor of poor prognosis in colorectal cancer. Br J Cancer. 2011;105:666-72.

25. Larsson A, Fridberg M, Gaber A, Nodin B, Levéen P, Jönsson G, Uhlén M, Birgisson $\mathrm{H}$, Jirström K. Validation of podocalyxin-like protein as a biomarker of poor prognosis in colorectal cancer. BMC Cancer. 2012;12:1.

26. Laitinen A, Böckelman C, Hagström J, Kokkola A, Fermér C, Nilsson O, Haglund C. Podocalyxin as a prognostic marker in gastric cancer. PLoS One. 2015;10:e0145079.

27. Flores-Téllez TNJ, Lopez TV, Vásquez Garzón VR, Villa-Treviño S. Coexpression of ezrin-CLIC5-podocalyxin is associated with migration and invasiveness in hepatocellular carcinoma. PLoS One. 2015;10:e0131605.

28. Snyder KA, Hughes MR, Hedberg B, Brandon J, Hernaez DC, Bergqvist P, Cruz F, Po K, Graves ML, Turvey ME, Nielsen JS, Wilkins JA, McColl SR, Babcook JS, Roskelley CD, McNagny KM. Podocalyxin enhances breast tumor growth and metastasis and is a target for monoclonal antibody therapy. Breast Cancer Res. 2015;17:46.
29. Lin C-W, Sun M-S, Wu H-C. Podocalyxin-like 1 is associated with tumor aggressiveness and metastatic gene expression in human oral squamous cell carcinoma. Int J Oncol. 2014;45:710-8.

30. Amo L, Tamayo-Orbegozo E, Maruri N, Buqué A, Solaun M, Riñón M, Arrieta A, Larrucea S. Podocalyxin-like protein 1 functions as an immunomodulatory molecule in breast cancer cells. Cancer Lett. 2015;368:26-35.

31. Schopperle WM, Lee JM, DeWolf WC. The human cancer and stem cell marker podocalyxin interacts with the glucose-3-transporter in malignant pluripotent stem cells. Biochem Biophys Res Commun. 2010;398:372-6.

32. Huang Z, Huang $Y, \mathrm{He} H, \mathrm{Ni}$ J. Podocalyxin promotes cisplatin chemoresistance in osteosarcoma cells through phosphatidylinositide 3kinase signaling. Mol Med Rep. 2015;12:3916-22.

33. Fristedt R, Gaber A, Hedner C, Nodin B, Uhlén M, Eberhard J, Jirstrom K. Expression and prognostic significance of the polymeric immunoglobulin receptor in esophageal and gastric adenocarcinoma. J Transl Med. 2014;12:83.

34. Jonsson L, Hedner C, Gaber A, Korkocic D, Nodin B, Uhlén M, Eberhard J, Jirström K. High expression of RNA-binding motif protein 3 in esophageal and gastric adenocarcinoma correlates with intestinal metaplasia-associated tumours and independently predicts a reduced risk of recurrence and death. Biomark Res. 2014;2:11.

35. Hedner C, Gaber A, Korkocic D, Nodin B, Uhlén M, Kuteeva E, Johannesson $\mathrm{H}$, Jirström K, Eberhard J. SATB1 is an independent prognostic factor in radically resected upper gastrointestinal tract adenocarcinoma. Virchows Arch. 2014;465:649-59.

36. Hedner C, Tran L, Borg D, Nodin B, Jirström K, Eberhard J. Discordant human epidermal growth factor receptor 2 overexpression in primary and metastatic upper gastrointestinal adenocarcinoma signifies poor prognosis. Histopathology. 2016:68:230-40.

37. Hedner C, Borg D, Nodin B, Karnevi E, Jirström K, Eberhard J. Expression and prognostic significance of human epidermal growth factor receptors 1 and 3 in gastric and esophageal adenocarcinoma. PLoS One. 2016;11:e0148101.

38. Lauren P. The two histological main types of gastric carcinoma: diffuse and so-called intestinal-type carcinoma. An attempt at a histo-clinical classification. Acta Pathol Microbiol Scand. 1965;64:31-49.

39. The Human Protein Atlas. http://www.proteinatlas.org/ENSG00000128567PODXL/antibody, accessed on 6 Feb 2016.

40. Larsson AH, Nodin B, Syk I, Palmquist I, Uhlén M, Eberhard J, Jirstrom K. Podocalyxin-like protein expression in primary colorectal cancer and synchronous lymph node metastases. Diagn Pathol. 2013;8:109.

41. Kaprio T, Fermér C, Hagström J, Mustonen H, Böckelman C, Nilsson O, Haglund C. Podocalyxin is a marker of poor prognosis in colorectal cancer. BMC Cancer. 2014;14:1.

\section{Submit your next manuscript to BioMed Central and we will help you at every step:}

- We accept pre-submission inquiries

- Our selector tool helps you to find the most relevant journal

- We provide round the clock customer support

- Convenient online submission

- Thorough peer review

- Inclusion in PubMed and all major indexing services

- Maximum visibility for your research

Submit your manuscript at www.biomedcentral.com/submit 